\title{
Major Depressive Disorder Complicated with Spinocerebellar Ataxia: Report of 2 Cases
}

\author{
Nagahisa Okamoto ${ }^{a}$ Masafumi Ogawa $^{b}$ Yoshiko Murata $^{b}$ \\ Kota Sakamoto ${ }^{a}$ Tatsuya Nagai $^{a}$ Maki Yamada ${ }^{a}$ \\ Teruhiko Higuchi ${ }^{\mathrm{a}}$
}

Departments of a Psychiatry and ${ }^{b}$ Neurology, National Center Hospital of Neurology and Psychiatry, Kodaira, Tokyo, Japan

\section{Key Words}

Major depressive disorder - Spinocerebellar ataxia - Spinocerebellar degeneration . Selective serotonin reuptake inhibitor - Treatment

\begin{abstract}
Background: It is known that patients with spinocerebellar ataxia (SCA) tend to exhibit depressive symptoms. But the pathology of depressive symptoms complicated with SCA, including the reaction to the stress resulting from decreased motor function and central dysfunction due to neurodegeneration, is controversial and remains to be elucidated. To our knowledge, there have been hardly any reports on treatment methods of major depressive disorder (MDD) complicated with SCA.

Case Reports: We report 2 cases in which selective serotonin reuptake inhibitors (SSRIs) were effective against MDD complicated with SCA. Interestingly, one of the patients developed the symptoms of spinocerebellar degeneration (SCD) during the course of the MDD, and the other patient developed the symptoms of MDD during the course of SCA, but complete remission of the MDD occurred in both cases. In our cases, the depressive symptoms may have been caused mainly by an abnormality of reversible neural transmission including serotonin transmission due to central dysfunction, and there is the unlikely possibility that the depressive symptoms are reactive to the stress due to decreased motor function, because the depressive symptoms decreased with SSRIs. Conclusion: Although cerebellar degeneration is irreversible in SCA patients, our cases suggest that MDD complicated with SCA may be reversible and treatable using antidepressants such as SSRIs with few adverse events. Therefore, it is important for neurologists to detect MDD complicated with SCA early and consult a psychiatrist in order to improve quality of life of SCA patients.
\end{abstract}




\begin{tabular}{c|l|l|l}
$\begin{array}{c}\text { Case Reports in } \\
\text { Neurology }\end{array}$ & $\begin{array}{l}\text { Case Rep Neurol 2010;2:52-56 } \\
\text { Dol: } 10.1159 / 000314406\end{array}$ & & $\begin{array}{l}\text { Published online: May 12, 2010 S. Karger AG, Basel } \\
\text { ISSN 1662-680X } \\
\text { www.karger.com/crn }\end{array}$ \\
\hline
\end{tabular}

\section{Introduction}

It is known that patients with spinocerebellar ataxia (SCA) tend to exhibit depressive symptoms. But there have been hardly any reports regarding treatment of major depressive disorder (MDD) complicated with SCA. The side effects of conventional antidepressants such as tricyclic antidepressants are attributed to their nonspecific interaction with cholinergic, histaminergic, serotonergic, and dopaminergic receptors in the central nervous system, and they often cause various adverse events [1]. Therefore, antidepressants that do not have this nonspecific interaction, such as the selective serotonin reuptake inhibitors (SSRIs), have recently been preferred in the treatment of MDD because of their tolerability. Especially in patients with MDD complicated with neurodegenerative disease, it seems to be difficult to use antidepressants with a nonspecific interaction because of the patients' central vulnerability and their neurologic or autonomic symptoms. SCA consists of a heterogeneous group of neurodegenerative disorders. SSRIs seem to be valuable because they cause few adverse events due to their specific antidepressant action. We report 2 cases of MDD complicated with SCA who successfully responded to SSRIs.

\section{Case Reports}

\section{Case 1}

The patient is a 53-year-old woman. Her mother was diagnosed with probable SCA at 52 years of age and with MDD at 60 years of age. Her mother died at 72 years of age. Her mother's sister had been diagnosed with probable SCA.

At 49 years of age, the patient developed depressive symptoms, including a severely depressed mood in the morning, loss of interest, insomnia, fatigue, and somatic anxiety. She was diagnosed with MDD at a psychiatric clinic and treated with fluvoxamine $(150 \mathrm{mg} /$ day $)$ and milnacipran (125 $\mathrm{mg} /$ day). But the depressive symptoms worsened, and anorexia, weight loss ( $6 \mathrm{~kg}$ in 3 months), and suicidal ideation ensued. Therefore, at 50 years of age, she was referred to our hospital. No abnormal findings were observed on serum examinations, including of thyroid function. Her symptoms met all of the diagnostic criteria of DSM-IV for MDD, and her total score on the 17-item Hamilton Rating Scale for Depression (HDSR) was 32. Brain magnetic resonance imaging (MRI) showed diffuse atrophy of the cerebellar cortex (fig. 1), but there were no clear cerebellar manifestations. She was treated with clomipramine (150 mg/day), sulpiride ( $300 \mathrm{mg} /$ day), and amoxapine $(150 \mathrm{mg} /$ day $)$, but treatment was ineffective. At 51 years of age, the depressive symptoms completely ceased within 3 months after starting paroxetine ( $40 \mathrm{mg} /$ day). She then was able to perform housework without any problems.

At 52 years of age, she developed lightheadedness on standing, and midodrine ( $4 \mathrm{mg} /$ day) was started. However, the lightheadedness became severer, and she gradually began to experience slurred speech and dysphasia. At 54 years of age, she developed a wide-based gait and often fell while walking. In addition to predominantly truncal cerebellar ataxia, she was found to have autonomic nervous system manifestations (urinary frequency, orthostatic hypotension), pyramidal tract signs (hyperactive lower limb tendon reflexes), impaired ocular pursuit movements, limited sursumversion, dysarthria, and dysphasia. Head-up tilt test was positive. She was diagnosed with probable SCA. She did not wish to undergo genetic diagnosis. Her score on the Mini-Mental State Examination (MMSE) was 22, and her full-scale IQ on the Wechsler Adult Intelligence Scale (WAIS)-III was 63, revealing a mild cognitive disorder. Though the neurological symptoms gradually progressed, MDD was in remission for 3 years after the start of paroxetine.

\section{Case 2}

The patient is a 37-year-old male. His mother was diagnosed with probable SCA at 40 years of age, and she died at 58 years of age. Genetic testing revealed that four of his relatives were positive for SCA3. 


\begin{tabular}{c|l|l|l}
$\begin{array}{c}\text { Case Reports in } \\
\text { Neurology }\end{array}$ & $\begin{array}{l}\text { Case Rep Neurol 2010;2:52-56 } \\
\text { Dol: } 10.1159 / 000314406\end{array}$ & & $\begin{array}{l}\text { P 2010 S. Karger AG, Basel } \\
\text { ISSN 1662-680X } \\
\text { www.karger.com/crn }\end{array}$ \\
\hline
\end{tabular}

At 31 years of age, fine movements became difficult. He gradually began to experience lightheadedness on standing and diplopia. His gait became wide-based. At 34 years of age, he became aware of slurred speech and dysphasia, so he visited our hospital. Cerebellar ataxia of his limbs and trunk, autonomic nervous system signs (orthostatic hypotension), pyramidal tract signs (hyperactive tendon reflexes in his limbs), impaired ocular pursuit movements, dysarthria, and dysphasia were noted. Head-up tilt test was positive and he had an erectile disturbance. MMSE score was 27, but fullscale IQ on the WAIS-Revised was 66, revealing mild cognitive dysfunction. Brain MRI showed diffuse cerebellar atrophy (fig. 1). Analysis of the CAG repeats in the SCA3 locus revealed an expanded allele with 69 repeats, and he was diagnosed with SCA3. The symptoms progressed, and at 36 years of age he needed a wheelchair.

At 37 years of age, he developed a severe depressive mood in the morning associated with suicidal ideation and lost his appetite and hardly ate anything. His movements became extremely slow, and all he could do was lie in bed all day. Blood studies, including of thyroid function, showed no abnormalities. The patient fulfilled all of the diagnostic criteria of the DSM-IV for MDD and his total score on the HDSR-17 was 30 . He was treated with paroxetine $(20 \mathrm{mg} /$ day), and moderate improvement in the depressive symptoms was observed. But acute urinary retention developed, and paroxetine was switched to sertraline ( $75 \mathrm{mg} /$ day). Subsequently, the urinary retention resolved and the MDD remitted. Though the neurological symptoms gradually progressed, MDD was in remission for 1 year after the start of sertraline.

\section{Discussion}

SCA consists of a heterogeneous group of disorders that differ in the extent of the neuropathologica involvement of the cerebellum, brainstem, and basal ganglia. Patients with degenerative cerebellar diseases tend to exhibit depressive symptoms. A study [2] of patients with degenerative cerebellar diseases showed a high prevalence of all mood disorders (68\%) including MDD (35.5\%). Another study [3] showed that the depressive symptoms were most common in SCA3 patients (60\%), as opposed to $23-27 \%$ of patients with other types of SCA.

However, the pathology of depressive symptoms associated with SCA is controversial and remains to be elucidated. A direct correlation between Beck Depression Inventory scores and motor incapacitation was found in SCA3 patients [4]. Therefore, it was concluded that depressive symptoms rather seemed to be reactive than primarily related to the disease process itself.

Yet, an association with central dysfunction due to neurodegeneration and depressive symptoms has also been highlighted. It was suggested that the greater depressive complaints in SCA3 may be due to dysfunction of frontal-subcortical circuits in the basal ganglia, structures that are uniquely involved in SCA3 as opposed to the other subtypes [3]. Furthermore, in recent years, there has been emerging evidence suggesting that the cerebellum is involved in various psychiatric disorders [5], and the cerebellar degeneration may be associated with depressive symptoms.

In our cases, depressive symptoms may have been caused mainly by an abnormality of reversible neural transmission including serotonin transmission due to central dysfunction, and there is the unlikely possibility that the depressive symptoms are reactive to the stress due to decreased motor function, because the depressive symptoms remitted with SSRIs.

There have been hardly any reports on the treatment of MDD complicated with SCA, and the only reports that exist are of a case in which electroconvulsive therapy was effective against the catatonic stupor of psychotic depression [6] and a case in which ECT was effective against organic catatonia [7]. 


\begin{tabular}{c|l|l|l}
$\begin{array}{c}\text { Case Reports in } \\
\text { Neurology }\end{array}$ & $\begin{array}{l}\text { Case Rep Neurol 2010;2:52-56 } \\
\text { D0I: } 10.1159 / 000314406\end{array}$ & Published online: May 12, 2010 & $\begin{array}{l}\odot \text { 2010 S. Karger AG, Basel } \\
\text { ISSN 1662-680X } \\
\text { www.karger.com/crn }\end{array}$ \\
\hline
\end{tabular}

The symptoms of SCA developed during the course of MDD in case 1, and the symptoms of MDD developed during the course of SCA in case 2. However, complete remission of MDD was achieved with SSRIs in both cases.

\section{Conclusion}

Although cerebellar degeneration is irreversible in SCA patients, our cases suggest that MDD complicated with SCA may be reversible and treatable using antidepressants with small adverse events such as SSRIs. Therefore, it is important for neurologists to detect MDD complicated with SCA early and consult a psychiatrist in order to improve quality of life of SCA patients.

\section{Patients' Consent}

Written consent for publication in print and electronically was obtained from the patients.

Fig. 1. The cerebellar cortex can be seen to be atrophic on T1-weighted magnetic resonance images obtained in case 1 and case 2 .

\section{Case1}

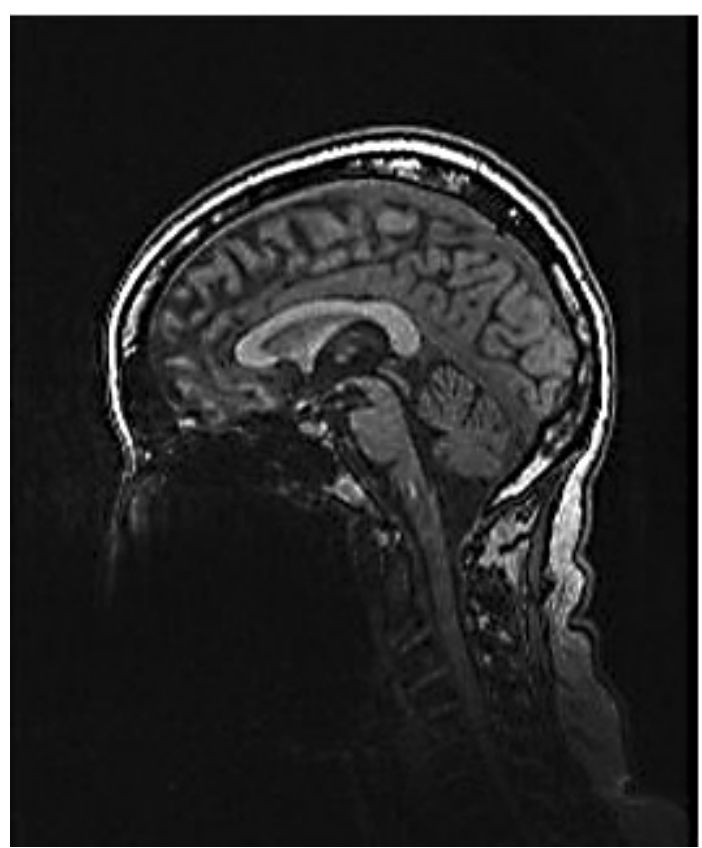

\section{Case2}

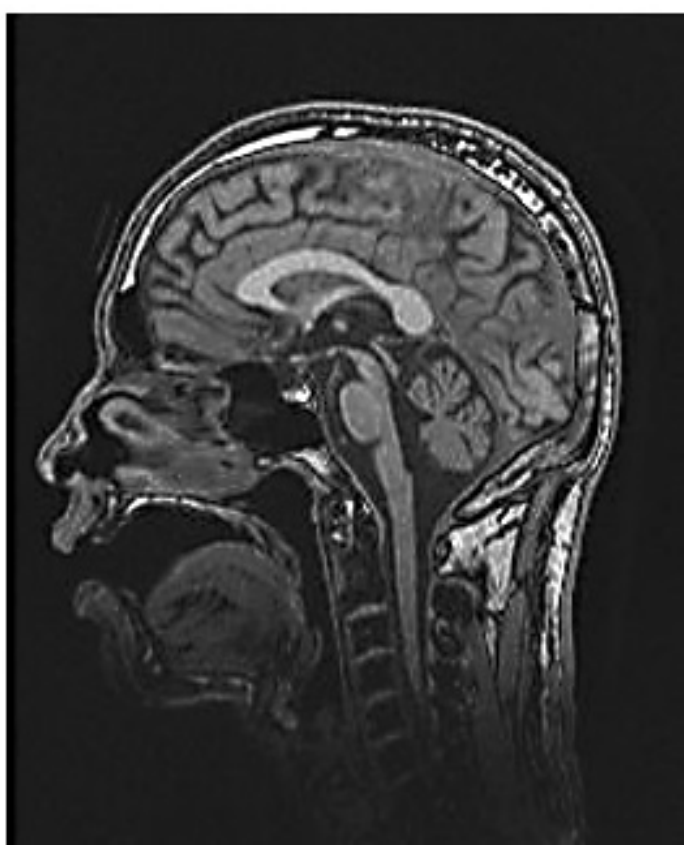




\begin{tabular}{c|l|l|l}
$\begin{array}{c}\text { Case Reports in } \\
\text { Neurology }\end{array}$ & $\begin{array}{l}\text { Case Rep Neurol 2010;2:52-56 } \\
\text { Dol: } 10.1159 / 000314406\end{array}$ & Published online: May 12, 2010 & $\begin{array}{l}\odot \text { 2010 S. Karger AG, Basel } \\
\text { ISSN 1662-680X } \\
\text { www.karger.com/crn }\end{array}$ \\
\hline
\end{tabular}

\section{References}

1 Andrews JM, Nemeroff CB: Contemporary management of depression. Am J Med 1994;97:24S-32S.

-2 Leroi I, O’Hearn E, Marsh L, Lyketsos CG, Rosenblatt A, Ross CA, et al: Psychopathology in patients with degenerative cerebellar diseases: a comparison to Huntington's disease. Am J Psychiatry 2002;159:1306-1314.

-3 McMurtray AM, Clark DG, Flood MK, Perlman S, Mendez MF: Depressive and memory symptoms as presenting features of spinocerebellar ataxia. J Neuropsychiatry Clin Neurosci 2006;18:420-422.

-4 Cecchin CR, Pires AP, Rieder CR, Monte TL, Silveira I, Carvalho T, et al: Depressive symptoms in Machado-Joseph disease (SCA3) patients and their relatives. Community Genet 2007;10:19-26.

5 Baldaçara L, Borgio JG, Lacerda AL, Jackowski AP: Cerebellum and psychiatric disorders. Rev Bras Psiquiatr 2008;30:281-289.

6 Suzuki K, Itou K, Takano T, Harada N, Awata S, Matsuoka H: Catatonic stupor superimposed on hereditary spinocerebellar degeneration resolved with electroconvulsive therapy. Prog Neuropsychopharmacol Biol Psychiatry 2006;30:1179-1181.

7 Folkerts HW, Stadtland C, Reker T: ECT for organic catatonia due to hereditary cerebellar ataxia. J ECT 1998;14:53-55.

Contribution: all authors participated in the management of the patient. N. Okamoto wrote the case report. 